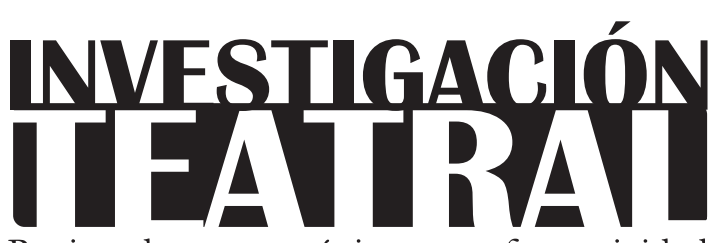

Revista de artes escénicas y performatividad

Vol. 9, Núm. 14

octubre 2018-marzo 2019

Segunda época

ISSN impreso: $1665-8728$

ISSN electrónico: 2594-0953

Testimonio:

Universidad Veracruzana

\title{
México pintoresco: un performance de exhibición etnográfica para la denuncia política
}

Itzel Aparicio*

\footnotetext{
* Maestría en Teatro y Artes Performáticas de la Universidad Nacional de las Artes de Buenos Aires, Argentina.

e-mail: itzelaparicioalarcon@gmail.com
}

Recibido: 09 de mayo de 2018

Aceptado: 30 de julio de 2018 


\title{
México pintoresco: un performance de exhibición etnográfica para la denuncia política
}

\section{Resumen}

México pintoresco es un performance de denuncia política que realizó la autora durante 2015 en Buenos Aires, Argentina, a unos meses de la desaparición de los 43 estudiantes de la Escuela Normal Rural de Ayotzinapa. En este testimonio se describe cómo, durante su estancia en esa ciudad, la autora presentó un performance de exhibición etnográfica para visibilizar la realidad política de México y dar pie a la protesta y denuncia del estado de emergencia de su país.

Palabras clave: Perfomance, denuncia, identidad, etnografía, desaparición, estudiantes, México, Buenos Aires.

\section{México Pintoresco: a Political Protest Performance based on an Ethnographic Display}

\begin{abstract}
Itzel Aparicio's political protest performance México pintoresco (Picturesque Mexico) took place in Buenos Aires, Argentina, a few months after the disappearance of the 43 students from the Normal Rural School of Ayotzinapa, Guerrero, Mexico. This testimony describes how, during her stay in the Argentinian capital, she strived to make visible the political reality of Mexico, and denounce the state of emergency in her country.
\end{abstract}

Keywords: Performance, protest, identity, ethnography, disappearance, students, Mexico, Buenos Aires. 


\section{México pintoresco: un performance de exhibición etnográfica para la denuncia política}

$\mathrm{D}$ urante el año 2015 hice una estancia en Buenos Aires, Argentina, para realizar estudios de posgrado en la Universidad Nacional de las Artes. Cambiar de país causó en mí una sensación de impotencia ante la situación que México enfrentaba respecto a la violencia de Estado y la desaparición de los 43 estudiantes. Me sentía frustrada y a la vez culpable por no accionar de alguna manera, ya fuera social o artísticamente, como lo estaban haciendo muchas personas y artistas de mi círculo social, aunado al temor de que la situación empeorara o llegara a afectar a mi familia durante mi ausencia. Esta sensación de coraje aumentó cuando, en mayo de ese mismo año, tomé un seminario llamado "Performatividades y teatralidades para dar la muerte, imaginar un lugar en la vida", impartido por Ileana Diéguez en el marco de la Bienal de Performance. Repasar los escenarios de violencia de la cotidianidad mexicana detonó, entre muchos de los mexicanos que cursamos ese seminario, un ímpetu por accionar y tomar partido acerca de la visibilización de lo acontecido con los estudiantes de Ayotzinapa. ${ }^{1}$

Como extranjera mexicana, me enfrenté una y otra vez a referencias, casi clichés, acerca de mi nacionalidad: el gusto por los chiles picantes, las playas del Caribe, lo colorido de nuestras vestimentas folclóricas y bailes, lo pintoresco de nuestra cultura, los mariachis, etcétera. La mayoría de mis primeros encuentros con desconocidos argentinos recaía en este tipo de referencias. Me di cuenta, entonces, de que podía echar mano de

1 Ayotzinapa es una localidad perteneciente al municipio de Tixtla de Guerrero en el estado de Guerrero, México, en la cual se encuentra la Escuela Normal Rural “Raúl Isidro Burgos”. El 26 de septiembre de 2014 se llevó a cabo la detención y desaparición forzada de 43 estudiantes de dicha Normal en Iguala, Guerrero. 
aquello que mi identidad proyectaba en el extranjero para alterar ese discurso de otredad y espectacularidad pintoresca o folclórica y hacer visible la realidad política y social por la que estaba pasando mi país. Fue a partir de las construcciones del "otro cultural" que me pregunté ¿qué imágenes o qué ideas sobre la mexicanidad se tienen en un país extranjero? ¿Qué significado cobran símbolos o elementos de la cultura mexicana en otro país y cómo éstos pueden ser utilizados para denunciar la violencia y represión bajo la que vive el pueblo mexicano?

El proceso de creación de mi performance de visibilización y denuncia fue largo. Hice muchas pruebas en distintos soportes (fotografía, video, intervención callejera) para llegar al resultado final. En una parte del proceso me acompañó la artista Ana Vértiz, compañera de posgrado, también mexicana, con la misma sensación de frustración y obligación artística sobre lo acontecido. Ambas hacíamos largas caminatas por la calle México, que cruza gran parte de la ciudad de Buenos Aires, y tomábamos registro de los carteles con los rostros de los estudiantes desaparecidos de Ayotzinapa y de las intervenciones gráficas con la leyenda "Estado Terrorista", que estaban colocadas junto a los rótulos de señalamiento de la calle México. En estos trayectos, Vértiz y yo pensábamos: ¿qué tipo de acción performática podríamos desarrollar para intervenir esa calle?

A la par de este proceso, en el programa de la maestría fui conociendo performances históricos con un fuerte posicionamiento de denuncia política. En particular me interesaron dos proyectos que me ayudarían a dar estructura a mi performance: Two Undiscovered Amerindians Visit... (Dos amerindios no descubiertos visitan...), de Coco Fusco y Guillermo Gómez Peña (1992-93) y La conquista de América, de las Yeguas del Apocalipsis (Pedro Lemebel y Francisco Casas), presentado en 1989. Ambos performances habían sido creados para presentarse en la conmemoración del Día de la Raza y poner en discusión, cada uno a su manera, la celebración del "descubrimiento" de América. Two Undiscovered Amerindians Visit... fue un performance creado para presentarse como respuesta crítica a la conmemoración de los 500 años de la llegada de Cristobal Colón a tierras americanas, en el cual Fusco (cubana-estadounidense) y Gómez-Peña (mexicano-chicano) se hicieron pasar por indígenas recién "descubiertos" y se exhibieron dentro de una jaula en espacios públicos y museos, rodeados de materiales que dieran cuenta de su "legitimidad" mientras que, a cambio de dinero, realizaban acciones "rituales" e interactuaban con el público. Según Fusco, el performance se inspiró en "la práctica europea y estadounidense alguna vez popular de exhibir a personas indígenas de África, Asia y el continente americano en zoológicos, parques, tabernas, museos, shows de fenómenos (freak shows) y circos" (Fusco 316). El performance tuvo lugar por vez primera en La Plaza Colón de Madrid, para después tener una gira de año y medio por distintas plazas y museos de Inglaterra, Estados Unidos y Argentina. 
Por su parte, el performance La conquista de América de Las Yeguas del Apocalipsis (dupla chilena conformada por Pedro Lemebel y Francisco Casas) fue presentado, todavía bajo el régimen dictatorial de Augusto Pinochet, el 12 de octubre de 1989 en la Comisión de Derechos Humanos de Santiago de Chile. Las Yeguas instalaron un mapa de Latinoamérica cubierto con vidrios de botellas de Coca-Cola rotas, sobre los que bailaban descalzos una cueca que sólo ellos escuchan a través de reproductores walkman que llevaban fijados al pecho. La cueca se había instaurado como el baile nacional chileno en la dictadura de Pinochet, por lo que -como acto de denuncia ante las desapariciones- las madres de los detenidos empezaron a bailar la "cueca sola". Al bailar la "cueca sola" descalzos, sobre el mapa de Latinoamérica, Las Yeguas llenaban de sangre el territorio, "trazando un paralelo entre el proceso colonial de 'la Conquista' y el soporte que el imperialismo norteamericano habría brindado a los gobiernos militares latinoamericanos" (Archivo Yeguas del Apocalipsis), al mismo tiempo que desplazan "la reclamación tradicional de los detenidos -desaparecidos hacia esos otros cuerpos invisibles, arrancados de todo nombre y recuerdo por su condición sexual" (López 122).

Me pareció que ambos performances dialogaban entre sí, al hacer una fuerte crítica y cuestionamiento al sistema de poder que legitima las prácticas, objetos o personas que son parte del acervo informativo sobre una cultura, además de develar la violencia a la que han sido sometidas las culturas no caucásicas colonizadas por el pensamiento occidental. Fue así que pensé en reunir las formas de presentación cultural a la que hacen referencia los performances anteriores: la puesta en escena de la exoticidad de "el otro" de Coco Fusco y Gómez-Peña y la utilización, por parte de Las Yeguas del Apocalipsis, de una práctica tradicional performática legitimada por el Estado para dar cuenta de la situación de emergencia política.

Para lograr esto, pensé en utilizar elementos que el extranjero inmediatamente relacionara con México: salsa, chiles, maíz, la bandera, colores, vestuario colorido y florido, danzas folclóricas, música tradicional, etcétera, y pensé en aprovechar mis conocimientos de música y zapateado de son jarocho ${ }^{2}$ para construir la acción que llegaría después a ser México pintoresco. Por lo tanto, en la siguiente etapa de creación de mi performance, realicé un video en la calle México, esquina con Defensa, que enfocaba a mis pies zapateando un ritmo de son jarocho sobre chiles verdes, maíz y jitomates. Ese ejercicio sería la base para el desarrollo del resultado final del performance.

A finales de ese año (2015), un grupo de artistas estudiantes del posgrado me invitó a formar parte de la muestra de performance "Genealogías Migratorias", en Delborde

2 Género de música popular del estado de Veracruz, México. 
INVESTIGACIÓNTEATRAL

Revista de artes escénicas y performatividad

Vol. 9, Núm. 14

octubre 2018-marzo 2019
México pintoresco: un performance de exhibición etnográfica para la denuncia política

Itzel Aparicio

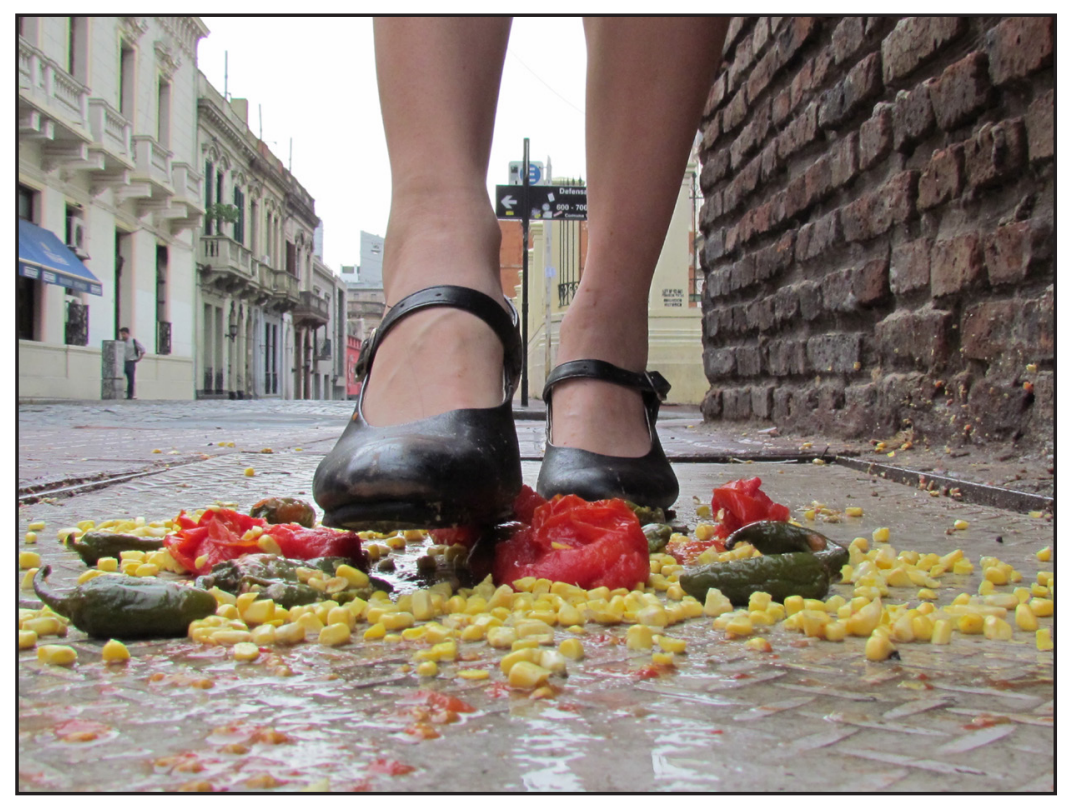

Ejercicio performático en la Calle México, esquina con Defensa. Buenos Aires, Argentina, 2015. Fotografía de Ana Vértiz.

Espacio Teatral. El evento convocó a siete artistas extranjeros, resididos en Buenos Aires, para establecer cruces de identidades, cultura y territorialidad en el transcurso del habitar otro país y contexto sociopolítico. Aquella muestra significó, entonces, la oportunidad perfecta para llevar a cabo mi acción de visibilización y denuncia acerca de lo que sucedía en mi país.

Para la etapa final de creación de México pintoresco convoqué al músico chileno Hernaldo Núñez para que colaborara en el diseño sonoro de la pieza, pues si ya había decidido zapatear, era preciso hacer uso de la música que estaba evocando y que es mundialmente conocida e identificada por uno de sus sones: "La bamba". Me pregunté entonces cómo, a través de un ritmo tan alegre, yo podía manifestar mi dolor y rabia acerca del tema que me aquejaba. Fue entonces que decidí usar los audios de videos que había repasado mil veces en las redes sociales acerca de protestas, pases de lista de los desaparecidos, persecuciones y tiroteos a estudiantes por parte del Estado. Seleccioné varios de ellos con estas características y le pedí a Hernaldo Núñez que hiciera una mezcla sonora con la música de "La bamba".

Por otro lado, en esta última etapa del proceso me valí del ejercicio de exhibición etnográfica que abordan las autoras Coco Fusco (en el texto "La otra historia del performance cultural") y Barbara Kirshenblatt-Gimblett (en el texto "Objetos de etnografía"), como un ejercicio de performance que pone particular acento en la acción humana y en el cuerpo, es decir, en la capacidad del exhibido de actuarse a sí mismo, problematizando las prácti- 
cas contemporáneas de escenificación de la otredad desde una visión occidental. Ambas proponen un quiebre en las manifestaciones verticales de poder que la etnografía en su práctica común lleva a cabo: una desde la "etnografía invertida", efecto que experimentaron Fusco y Gómez Peña al interactuar con el público entre los barrotes de la jaula de oro en Two Undiscovered Amerindians Visit..., sometiendo al público a su "propio proceso de reflexión respecto a lo que veía" (Fusco 315) y la otra desde el análisis de las condiciones de la puesta en escena.

México pintoresco fue estrenado el 4 de diciembre de 2015 en Delborde Espacio Teatral, en el marco de la antes mencionada muestra "Genealogías Migratorias", después de varios meses de proceso creativo. El resultado final fue el siguiente: me vestí con un atuendo tradicional mexicano sobre una tarima donde se exponían componentes de la gastronomía mexicana: chiles, maíz y jitomates, dispuestos de manera que remitían a la bandera de México. Realicé el performance bailando un zapateo tradicional de son jarocho encima de estos chiles verdes, granos de maíz y jitomates mientras se oía una pista sonora que mezclaba voces y sonidos que iban desde las palabras pronunciadas por el presidente Enrique Peña Nieto en el Día de la Independencia, música tradicional jarocha, estruendos de festividades; pasando por tiroteos, consignas de manifestaciones y ruidos de persecuciones por parte del Estado a estudiantes, para terminar con el audio del pase de lista de los 43 estudiantes de la Normal Rural de Ayotzinapa desaparecidos el 26 de septiembre de 2014 en Iguala, Guerrero. La acción del zapateo sucedía a lo largo del audio, aplastando los elementos que iban formando la imagen de la bandera mexicana. Poco a poco, esta bandera hecha de chiles, maíz y jitomates se comenzaba a transformar, por el impacto de los pies, en una mezcla densa y rojiza. Esta mezcla iba adquiriendo un aspecto sangriento que manchaba y se desbordaba del espacio sobre el que se ejecutaba la acción. Daba fin al performance, descalzándome y desapareciendo de escena para dejar a la vista la imagen de los zapatos vacíos sobre la mezcla "sangrienta" aplastada en el espacio, mientras se escuchan los nombres de los cuarenta y tres desaparecidos.

Para el performance retomé algunas características de la exhibición etnográfica que Kirshenblatt-Gimblett señala con el fin de presentarme a mí misma como objeto de exhibición de la cultura mexicana en Buenos Aires. Para esta investigadora, el objeto etnográfico, que puede ser también una persona, es en realidad un fragmento que se basa en una poética de la separación: "La separación se refiere no sólo al acto físico de producir fragmentos, sino también a la actitud de separación como distanciamiento que posibilita dicha fragmentación y su separación" (249). Esta fragmentación la lleva a cabo el etnógrafo o el responsable de la puesta en escena del fragmento, creando así objetos o constituyendo sujetos. Kirshenblatt distingue dos tipos de exhibición del fragmento: in situ y en contexto. Las exhibiciones in situ se valen de la mímesis para reproducir ambientes y crear conjuntos 
INVESTIGACIÓNTEATRAL

Revista de artes escénicas y performatividad

Vol. 9, Núm. 14

octubre 2018-marzo 2019
México pintoresco: un performance de exhibición etnográfica para la denuncia política

Itzel Aparicio

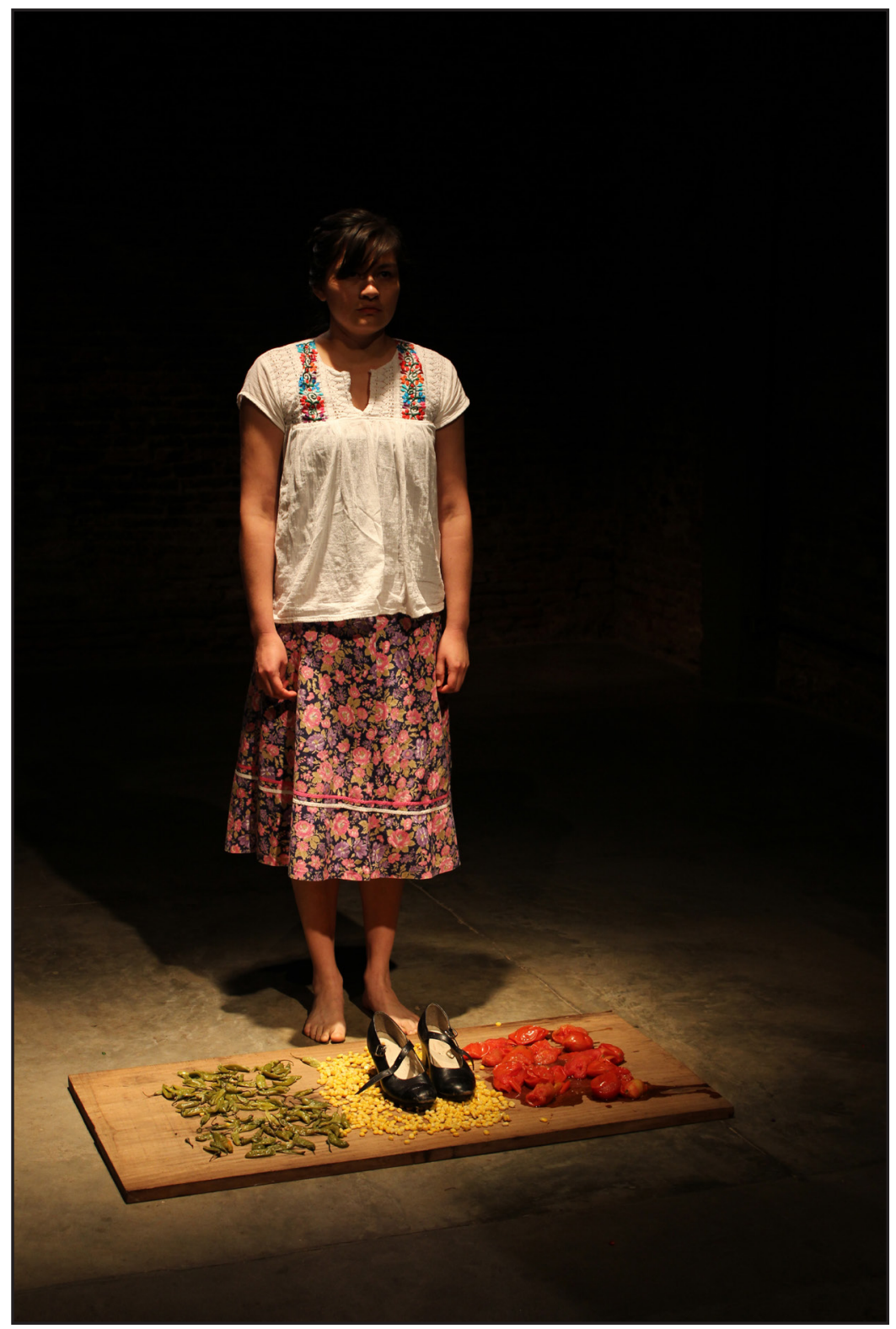

México pintoresco en la muestra de performance "Genealogías Migratorias". Delborde Espacio Teatral, Buenos Aires, Argentina, 2015. Fotografía de Isabel Toledo.

culturales artificiales. Estos conjuntos no están dados, sino que son constituidos a partir de convenciones representacionales. Las exhibiciones en contexto implican "técnicas particulares de organización y explicación para transmitir ideas" (251), así, a través de notas, diagramas, grabaciones de sonido, audiovisuales, folletos, conferencias, etcétera, se establece un marco teórico referencial para el espectador. Por lo que el curador de la exhibición es el 
INVESTIGACIÓNTEATRAL

Revista de artes escénicas y performatividad

Vol. 9, Núm. 14

octubre 2018-marzo 2019
México pintoresco: un performance de exhibición etnográfica para la denuncia política

Itzel Aparicio

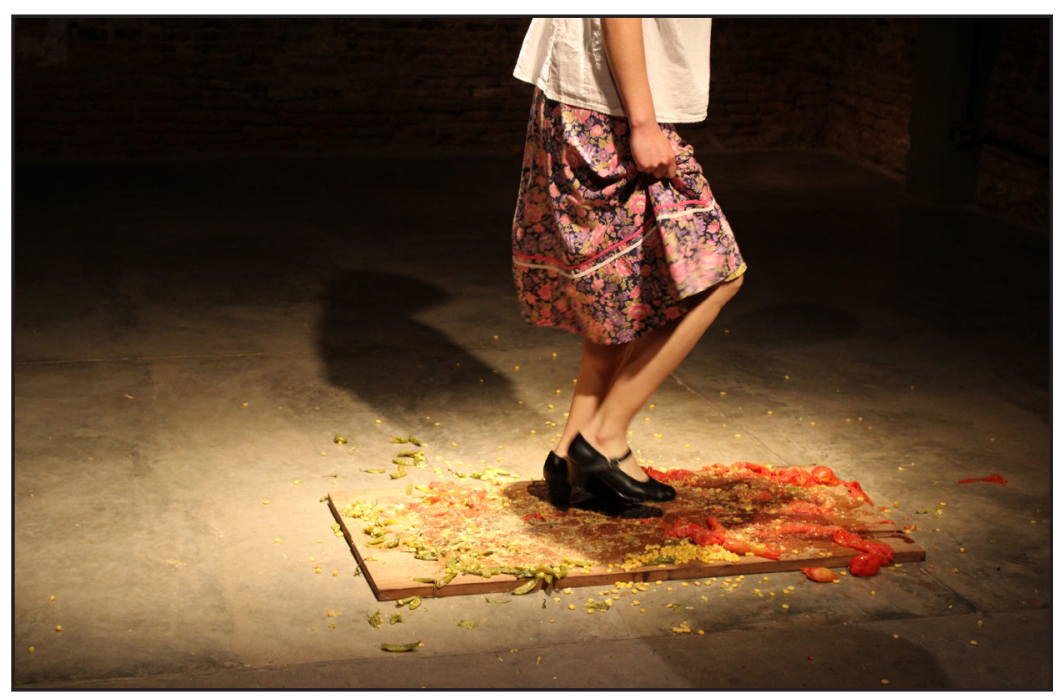

México pintoresco en la muestra de performance “Genealogías Migratorias". Delborde Espacio Teatral, Buenos Aires, Argentina, 2015. Fotografía de Isabel Toledo.

encargado de hacer hablar al objeto, de presentar el "drama del espécimen". De esta manera, en México pintoresco, fui tanto exhibidora como el sujeto que se exhibe con un atuendo que es parte del imaginario folclórico de mi país, desempeñando una acción perteneciente al acervo musical tradicional del mismo. Era esta forma de presentación de fragmentos in situ la que ayudó a construir mi discurso en el performance, al igual que la presentación en contexto que lo demarcó. México pintoresco no expuso información literal a partir de descripciones del objeto, sino que fue la mezcla de los audios que se escuchaban desde el comienzo del performance lo que contextualizó aquello que se estaba espectando. Según Kirshenblatt-Gimblett, la relación entre prácticas in situ y en contexto no es de ninguna manera excluyente, ya que ambas son necesarias en la constitución del sujeto exhibido. Es por ello que para mí era de vital importancia el contraste entre la exposición in situ y en contexto, pues es en esta contraposición que se generaba un choque entre la fascinación de lo exótico que se observó y el rechazo que generó lo que se escuchaba.

Presentar México pintoresco en esa muestra, junto con seis obras de artistas latinos extranjeros, me dio la oportunidad de abrir un diálogo en torno a mis frustraciones, enojos y tristezas respecto a mi nacionalidad y condición de extranjera en Buenos Aires. Si bien los argentinos no son tan lejanos a nuestra cultura -ya que comparten una historia latinoamericana de colonización y violencia de Estado- la mayoría de las veces el primer encuentro que establecía con ellos se enfocaba en el imaginario atractivo, pintoresco y estereotipado que mencioné antes. En cambio, para mí lo importante en esos meses era denunciar acontecimientos terribles que rompían por completo con ese imaginario del "México lindo y querido". Necesitaba denunciar al Estado represor mexicano, necesitaba que supieran que 
en México desaparecían estudiantes como yo. Esta necesidad de que el extranjero entendiera mi sentir y situación nacional durante el primer encuentro, pudo ser saciada con México pintoresco.

Fue muy revelador darme cuenta de cómo se transformaba durante el performance la primera impresión que se llevaban los espectadores al verme vestida "folclóricamente". Quizás la tabla con los chiles, maíz y jitomates generaban la expectativa de que iban a presenciar una danza alegre y festiva. El zapateando sobre estos elementos, sin embargo, generaba cierta tensión entre el público cuando las verduras se aplastaban y producían una "salsa" resbalosa y de fuerte olor picante, sobre la cual en ocasiones yo resbalaba. El audio de "La bamba", yuxtapuesta con los sonidos antes descritos, aumentaba la tensión. Al final, se escuchaba la lectura de la lista de nombres de los 43 desaparecidos, seguido por largos minutos de silencio de los espectadores.

El performance fue una gran sacudida para mí como creadora. Físicamente me requería concentración para no caer, quebrarme un pie ni enchilarme la garganta o los ojos con el picante que despedían los chiles, mientras me confrontaba internamente con el coraje y sentimiento sobre la situación expuesta durante el zapateado (cuya ejecución me ayudaba a liberar esas emociones).

Al finalizar la muestra, algunos espectadores argentinos se acercaron para comentarme su conmoción durante y después del performance. Me hicieron comentarios acerca de lo atractivo y terrible de la acción, del contraste discursivo respecto a lo que veían, escuchaban y comprendían. Pero lo más significativo es que lograron identificarse conmigo y con mi situación de dolor e impotencia porque su memoria política e histórica se había activado al presenciar la acción.

Casi un año después, el 2 de octubre de 2016, el performance fue presentado en el marco de la muestra "Acciones artísticas por Ayotzinapa", realizada en Casa Belgrano. Un grupo de artistas mexicanos también resididos en Buenos Aires se reunió en dicho evento para abordar, desde diferentes propuestas estéticas, la violencia, dolor, terrorismo de Estado y desaparición forzada en México. Estas mismas acciones -entre ellas México pintoresco- se volvieron a presentarse el 27 de octubre del mismo año dentro del $2^{\circ}$ Ciclo Libertad en el Centro Cultural Raíces de Buenos Aires.

Regresé a México a finales de 2016 y hasta la fecha no he presentado el performance en mi país. Me he preguntando si perdería fuerza, pues todo el planteamiento se suscitó a partir de mi condición de extranjera en Buenos Aires, de una necesidad profunda de identificación y contención con el otro por la realidad personal, política y social que estaba viviendo en ese momento. Hoy, a cuatro años de la desaparición de los 43 estudiantes de Ayotzinapa, México sigue arrastrando una memoria de dolor, impotencia y coraje respecto a este hecho y a muchos otros que se han ido acumulando a lo largo del sexenio que está a 
punto de terminar. Escribir este testimonio ha removido y activado nuevamente en mí esa memoria. Hoy pienso que valdría la pena realizar una nueva versión de México pintoresco, pues es urgente seguir denunciando que los 43 estudiantes, junto con miles de personas más, aún no aparecen.

\section{Bibliografía}

Aparicio, Itzel. México pintoresco. Muestra “Genealogías Migratorias”. Delborde Espacio Teatral, Buenos Aires, Argentina, 4 de diciembre de 2015.

Archivo Yeguas del Apocalipsis. "La conquista de América". Yeguas del Apocalipsis. Fondo Nacional de Desarrollo Cultural y las Artes, en línea. Consultado el 3 de febrero de 2018.

Fusco, Coco. "La otra historia del performance intercultural". Estudios Avanzados de Performance. Eds. Diana Taylor y Marcela Fuentes. México: Fondo de Cultura Económica, 2011, pp. 305-342.

Gómez-Peña, Guillermo. “Dioramas vivientes y agonizantes. El performance como una estrategia de antropología inversa”. Hemispheric Institute Biblioteca de Video Digital. Instituto Hemisférico de Performance y Política, 1999, en línea. Consultado el 20 de julio de 2018.

Kirshenblatt-Gimblett, Bárbara. "Objetos de etnografía”. Estudios Avanzados de Performance. Eds. Diana Taylor y Marcela Fuentes. México: Fondo de Cultura Económica, 2011, pp. 241-303.

López, Miguel Ángel. "Fosa Común”. Perder la forma humana. Una imagen sísmica de los años ochenta en América Latina. Red Conceptualismos del Sur. Madrid: Museo Nacional Centro de Arte Reina Sofía, 2013. pp. 116-126. 